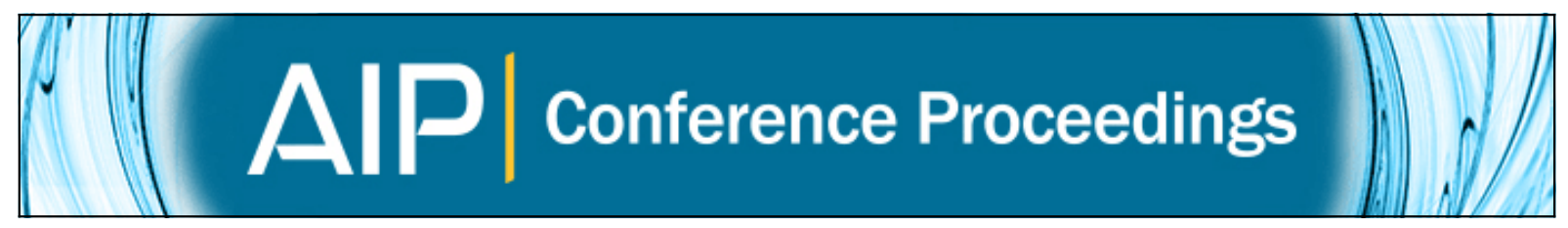

\title{
The PETRA III extension
}

W. Drube, M. Bieler, W. A. Caliebe, H. Schulte-Schrepping, J. Spengler, M. Tischer, and R. Wanzenberg

Citation: AIP Conference Proceedings 1741, 020035 (2016); doi: 10.1063/1.4952814

View online: http://dx.doi.org/10.1063/1.4952814

View Table of Contents: http://scitation.aip.org/content/aip/proceeding/aipcp/1741?ver=pdfcov

Published by the AIP Publishing

\section{Articles you may be interested in}

Photon beamline frontends for the PETRA III extension project

AIP Conf. Proc. 1741, 020041 (2016); 10.1063/1.4952820

Properties of the insertion devices for PETRA III and its extension

AIP Conf. Proc. 1741, 020019 (2016); 10.1063/1.4952798

The Generic Beamline Concept of the PETRA III Undulator Beamlines

AIP Conf. Proc. 879, 539 (2007); 10.1063/1.2436117

Insertion Devices for the PETRA III Storage Ring

AIP Conf. Proc. 879, 343 (2007); 10.1063/1.2436070

PETRA III - Status of the Storage Ring

AIP Conf. Proc. 879, 175 (2007); 10.1063/1.2436034 


\title{
The PETRA III Extension
}

\author{
W. Drube ${ }^{\text {a) }}$, M. Bieler, W. A. Caliebe, H. Schulte-Schrepping, J. Spengler, \\ M. Tischer, R. Wanzenberg
}

Deutsches Elektronen-Synchrotron DESY, 22603 Hamburg, Germany

${ }^{a}$ Corresponding author: wolfgang.drube@desy.de

\begin{abstract}
The $3^{\text {rd }}$ generation low-emittance $6 \mathrm{GeV}$ PETRA III facility has been substantially modified to add new beamlines. This extension project involved the complete removal and reconstruction of part of the storage ring with a double-bend achromat lattice as well as the construction of two new experimental halls. Making use of two long straight sections and a canted undulator scheme in the rebuilt arcs, up to ten new insertion device beamlines can be accommodated. In the current phase of the project, seven insertion device and one bending magnet beamline are being implemented.
\end{abstract}

\section{OVERVIEW}

PETRA III is a low-emittance $6 \mathrm{GeV}$ storage ring having evolved from the conversion of the $2.3 \mathrm{~km}$ PETRA accelerator into a $3^{\text {rd }}$ generation light source since 2007 [1]. Today, a total of 14 undulator beamlines with 15 experimental stations operating in parallel for high-brilliance techniques are in user operation in the Max-von-Laue experimental hall which covers $1 / 8$ of the storage ring. In order to extend the experimental capabilities with more beamlines, a major reconstruction started in February 2014 adding two smaller halls in the north and the east of the present Max-von-Laue hall by making use of two long straight sections and part of the adjacent arcs (Fig. 1) [2].

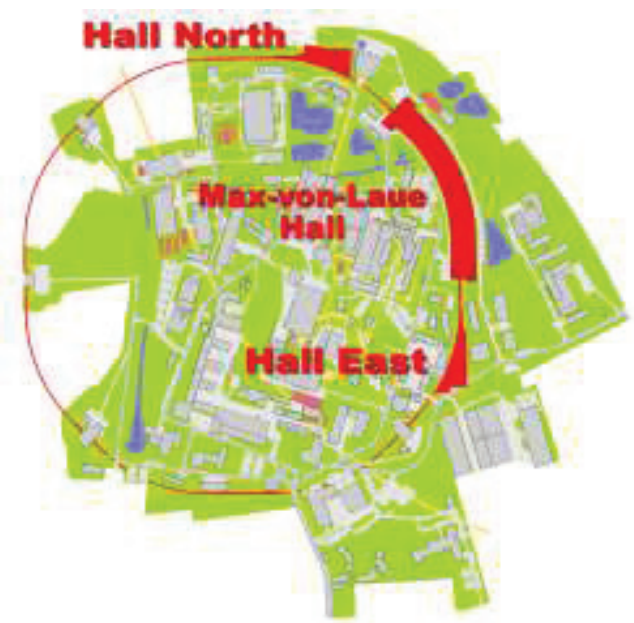

FIGURE 1 Two new experimental halls in the north and the east have been added to the PETRA III storage ring. The initial 14 beamlines are located in the Max-von-Laue hall.
The northern straight section already accommodates a series of damping wigglers producing an extremely hard Xray beam while the eastern straight is available for additional insertion devices (IDs). For the implementation of ID beamlines also in the original arcs, the machine lattice had to be modified to allow for suitable straight sections. Due to the large machine radius, the use of the arc sections for X-ray bending magnet beamlines is not feasible. During the reconstruction, the existing ring tunnel at the site of the new buildings had been completely removed and rebuilt as part of the experimental halls. In the east, the tunnel lies below ground level resulting in a complex reconstruction scenario. After eleven months of shutdown, the rebuilt machine had been re-commissioned for operation of the existing beamlines while in parallel the completion of the new halls and installation of new beamlines continued [3]. The initial project phase comprising the implementation of seven new X-ray ID beamlines and one VUV bending magnet beamline will be completed in 2018. 


\section{STORAGE RING RECONSTRUCTION}

In order to allow for the use of insertion devices in the northern and eastern arc sections, the existing cell structure (with $5.3 \mathrm{~m}$ long dipoles) has been partly replaced by double-bend achromat (DBA) cells using $1 \mathrm{~m}$ and 0.5 $\mathrm{m}$ dipoles. Similar to beamlines in the Max-von-Laue hall, the straight sections between the DBA cells are shared by

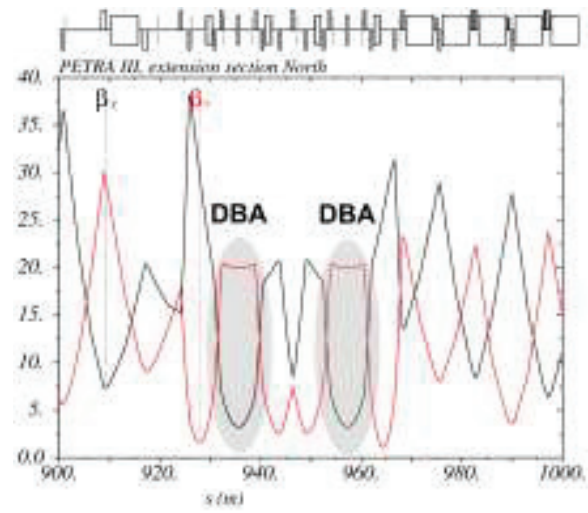

FIGURE 2 New optics with two DBA cells. two independent $2 \mathrm{~m}$ long IDs by using a canting dipole in the middle of each cell. For the PETRA III Extension, a canting angle of $20 \mathrm{mrad}$ was chosen to allow for sufficient space downstream for photon science instrumentation. The new lattice configuration with two DBA cells is shown in Fig. 2 for the northern arc. A high- $\beta$ optics was chosen for all ID sources. The lattice modification implies a change in the synchrotron integrals $\mathrm{I}_{2}$ and $\mathrm{I}_{5}$ resulting in a $20 \%$ emittance increase. The measured horizontal emittance after storage ring re-commissioning was $1.2 \mathrm{nmrad}$, the coupling being $1 \%$. The main machine parameters are summarized in Tab. 1.

Two $60 \mathrm{~m}$ long arc sections of the storage ring, adjacent to the long straights, were completely reconstructed. In order to accommodate the beamline front ends, $80 \mathrm{~m}$ long segments of the concrete tunnel were demolished and later rebuilt as part of the new experimental halls on a common thick concrete slab together with the canted beamlines. Both straight section IDs, however, remain on the original, separate concrete foundation.

The damping wiggler section was left unchanged, only the end piece of the high-power photon absorber will be replaced to extract a $3 \times 2 \mathrm{~mm}^{2}$ cross section of the on-axis photon beam. The downstream part of the eastern long straight section (total length $108 \mathrm{~m}$ ) will be modified to realize two straights of $5 \mathrm{~m}$ length with $\beta_{\text {hor }}=20 \mathrm{~m}$ and $\beta_{\text {vert }}=$ $3.5 \mathrm{~m}$ for use of a $4 \mathrm{~m}$ long in-vacuum undulator and a canted (1mrad) $2 \mathrm{~m}$ long side station ID. The new ID vacuum chambers (extruded NEG-coated aluminum profiles with 7 $\mathrm{mm}$ aperture) allow for a minimum magnetic gap of $9.5 \mathrm{~mm}$. The impedance increase is about $40 \%$, which is expected to be compatible with 40 bunch mode operation at $100 \mathrm{~mA}$ total current.

TABLE 1 PETRA III parameters incl. extension

\begin{tabular}{lccc}
\hline Parameter & & \\
Energy & \multicolumn{2}{c}{6} & $\mathrm{GeV}$ \\
Circumference & \multicolumn{2}{c}{2304} & $\mathrm{~m}$ \\
Emittance (hor. / vert.) & \multicolumn{2}{c}{$1.2 / 0.012$} & $\mathrm{~nm} \mathrm{rad}$ \\
Total current & \multicolumn{2}{c}{100} & $\mathrm{~mA}$ \\
Number of bunches & 960 & 40 & \\
Bunch population & 0.5 & 12 & $10^{10} \mathrm{e}^{-}$ \\
Bunch separation & 8 & 192 & $\mathrm{~ns}$ \\
\hline
\end{tabular}

\section{INSERTION DEVICES AND BEAMLINE FRONT ENDS}

In the northern straight section, beamline P61 will use the existing damping wiggler (DW) structure as a source consisting of ten $4 \mathrm{~m}$ long fixed-gap wigglers with $\mathrm{K}_{\max }=28.4$. The eastern long straight section will be equipped with a short period $\left(\lambda_{U}=21.2 \mathrm{~mm}\right)$ in-vacuum undulator ( $4 \mathrm{~m}$ magnetic length) optimized for high energy applications at beamline P21. It will be used mainly above its $5^{\text {th }}$ harmonic of $41.5 \mathrm{keV}$. In addition, the side station at this beamline will be fed from a $2 \mathrm{~m}$ long U29 undulator in the canted straight.

Spectroscopy beamlines P22 and P64 will be equipped with 2m long U33 undulators with period lengths of $32.8 \mathrm{~mm}$. With $\mathrm{K}_{\max }=2.7$ these devices will reach a minimum photon energy of $2.3 \mathrm{keV}$ in the $1^{\text {st }}$ harmonic and are fully tunable. Spectroscopy beamline P65 will initially use a compact, water-cooled double-crystal monochromator (DCM), which had been very successfully used at DORIS III bending magnet beamlines. This device may not be exposed to the heatload of a long undulator, instead a short U33 with 10 periods will be used initially. Since its magnetic design and mechanical support structure are identical to the respective $2 \mathrm{~m}$ device, a later upgrade is easily accomplished. The main characteristics of all IDs used at the PETRA III extension beamlines are summarized in Table 2 [4,5]. For comparison, the power of the damping wiggler section has been calculated through a $1 \times 1 \mathrm{~mm}^{2}$ pinhole at $40 \mathrm{~m}$ behind the last wiggler.

The design of the new beamlines is based on the PETRA III generic beamline concept $[6,7]$. All frontend components have been pre-assembled and aligned on girders for precise and timely installation during the reconstruction (Fig. 3). The canted beamlines are crossing the tunnel concrete shielding at $50 \mathrm{~m}$ from the source 
resulting in considerable total lengths up to $110 \mathrm{~m}$, beamline P21 - using the eastern long straight section - extends up to $164 \mathrm{~m}$. The canted beamlines in sectors 2 and 3, i.e. the modified arc sections, share a common optics hutch in each sector for the X-ray optical components such as monochromators, primary mirrors, etc.

TABLE 2: Insertion device parameters (beam current $100 \mathrm{~mA}$ )

\begin{tabular}{lcccccc}
\hline & DW & U21 & U29 & U32 & U33 & U33s \\
\hline minimum magnetic gap $(\mathrm{mm})$ & 24 & 7.0 & 9.5 & 9.5 & 9.5 & 9.5 \\
period length $\lambda_{\mathrm{U}}(\mathrm{mm})$ & 200 & 21.2 & 29.0 & 31.4 & 32.8 & 32.8 \\
device length $\mathrm{L}(\mathrm{m})$ & $10 \times 4$ & 4 & 2 & 2 & 2 & 0.41 \\
number of periods & $10 \times 19$ & 184 & 67 & 61 & 58 & 10 \\
peak field $\mathrm{B}_{0}(\mathrm{~T})$ & 1.52 & 0.71 & 0.81 & 0.91 & 0.88 & 0.88 \\
deflection parameter $\mathrm{K}_{\max }$ & 28.4 & 1.41 & 2.2 & 2.7 & 2.7 & 2.7 \\
${\text { energy of } 1^{\text {st }} \text { harmonic }(\mathrm{keV})}_{\text {total power } \mathrm{P}_{\text {tot }}(\mathrm{kW})}^{35.8\left(\mathrm{E}_{\mathrm{c}}\right)}$ & 8.3 & 3.5 & 2.4 & 2.3 & 2.3 \\
on axis power density $\left(\mathrm{kW} / \mathrm{mrad}^{2}\right)$ & $10 \times 21$ & 4.6 & 3.0 & 3.8 & 3.5 & 0.60 \\
power in $1 \mathrm{x} 1 \mathrm{~mm}^{2}$ at $40 \mathrm{~m}(\mathrm{~W})$ & $10 \times 44$ & 188 & 76 & 80 & 75 & 13 \\
\hline
\end{tabular}

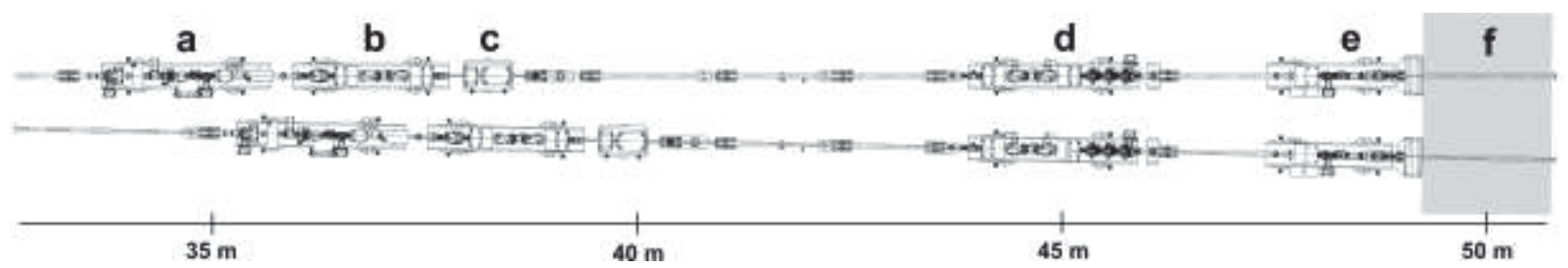

FIGURE 3 Frontend of a canted undulator sector. a: CVD diamond screen and vacuum valve b: vertical slits c: dump magnet d: vert./hor. photon shutter slit system and filter unit e: Bremsstrahlung collimator and beamstop f: concrete shielding wall

\section{BEAMLINES}

In the current project phase, seven insertion device and one bending magnet beamline are being implemented, whereof three ID beamlines are realized in collaboration with international partners. Four ID beamlines for hard Xray techniques are being built in hall east (P21-P24) and three in hall north (P61, P64-65) while three beamports (P62-63, P25) are left open for future options (beyond 2018). A bending magnet beamline (P66) for VUV spectroscopy is located in a separate enclosure outside hall north. Beamlines P22-23, 64 will be equipped with an

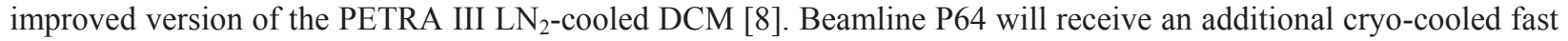
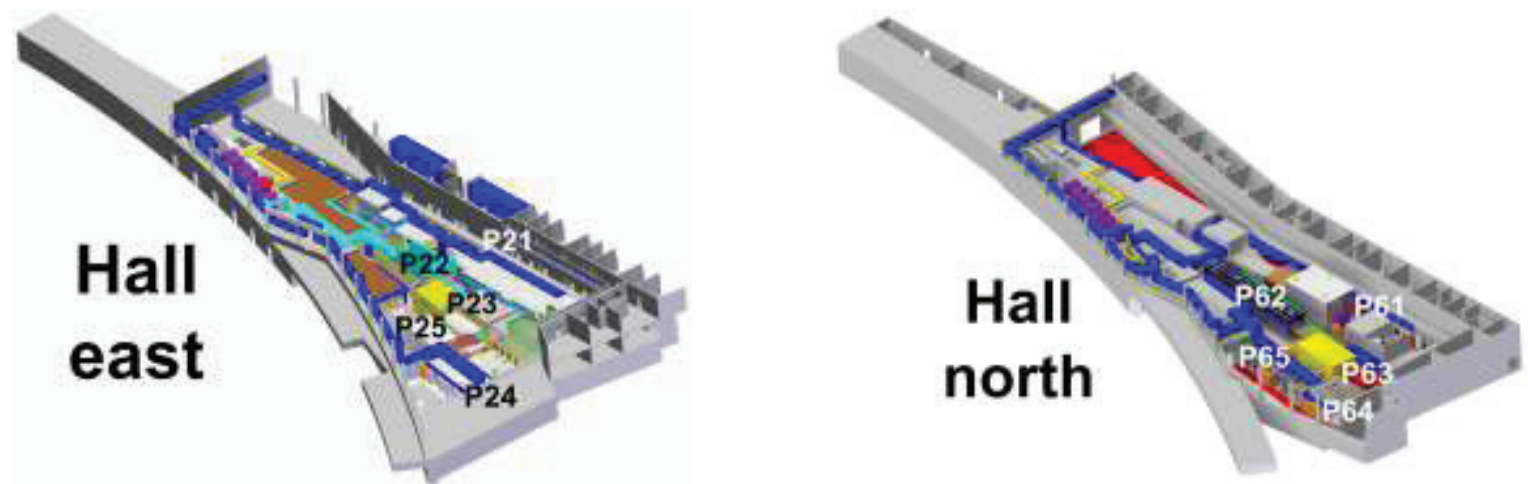

FIGURE 4 Beamline floor plan in the new experimental halls north and east of the Max-von-Laue Hall. Beamlines P21 and P61 are fed from insertion devices in the long straights, beamlines P21-25 and P62-65 are canted undulator beamlines in the arcs. 
scanning channel-cut monochromator for time-resolved X-ray absorption spectroscopy. Table 3 summarizes the main characteristics of the new beamlines, which will be implemented in three stages. Stage 1 beamlines P64-65 for XAFS applications are planned to start commissioning in Sept. 2015.

TABLE 3. PETRA III Extension beamlines. Beamlines are distributed between hall east (P21-25) and hall north (P61-65). Bending magnet beamline P66 is separate and close to hall north.

\begin{tabular}{|c|c|c|c|}
\hline Beamline & Applications/Instruments & Insertion Device & $\begin{array}{c}\text { Energy } \\
\text { Range (keV) }\end{array}$ \\
\hline P21 & $\begin{array}{l}\text { High-energy X-ray materials science (Swedish beamline) } \\
\text { broad band diffraction (fixed-energy side station) } \\
\text { in-situ WAXS/SAXS and imaging }\end{array}$ & $\begin{array}{c}2 \mathrm{~m} \mathrm{U} 29 \\
4 \mathrm{~m} \text { in-vac. } \mathrm{U} 21\end{array}$ & $\begin{array}{l}52,85,100 \\
40-150\end{array}$ \\
\hline $\mathrm{P} 22$ & $\begin{array}{l}\text { X-ray spectroscopy (Indian-German beamline) } \\
\text { hard X-ray photoemission }^{1} \text { and energy filtered } \text { PEEM }^{2}\end{array}$ & $2 \mathrm{~m} \mathrm{U} 33$ & $2.4-15$ \\
\hline $\mathrm{P} 23$ & $\begin{array}{l}\text { X-ray nano-diffraction }{ }^{3} \text { (German-Russian beamline) } \\
\text { X-ray diffractometry at meso- and nanoscopic scales }\end{array}$ & $2 \mathrm{~m} \mathrm{U} 32$ & $5-35$ \\
\hline P24 & $\begin{array}{l}\text { Chemical crystallography : materials \& small molecules } \\
\text { in complex sample environments }{ }^{1}\end{array}$ & $2 \mathrm{~m} \mathrm{U} 29$ & $\begin{array}{c}8 \text { and } \\
15-44\end{array}$ \\
\hline P25 & t.b.d. & t.b.d. & \\
\hline P61 & $\begin{array}{l}\text { High-energy X-ray materials science } \\
\text { engineering materials diffraction techniques }(\mathrm{HZG})^{4} \\
\text { extreme conditions in a large volume press }{ }^{1}(\mathrm{DESY})\end{array}$ & $\begin{array}{l}\text { 10x4m damping } \\
\text { wigglers }\end{array}$ & $\begin{array}{l}40-200 \\
\text { monochr. } \\
\text { and pink }\end{array}$ \\
\hline $\mathrm{P} 62 / \mathrm{P} 63$ & t.b.d. & t.b.d. & \\
\hline P64 & $\begin{array}{l}\text { X-ray absorption spectroscopy: high-flux applications } \\
\text { QEXAFS }^{1} \text {, highly-diluted samples, HERFD-XAFS }\end{array}$ & $2 \mathrm{~m} \mathrm{U} 33$ & $4-44$ \\
\hline P65 & $\begin{array}{l}\text { X-ray absorption spectroscopy: } \\
\text { applied XAFS on bulk materials }\end{array}$ & $0.4 \mathrm{~m} \mathrm{U} 33$ & $4-44$ \\
\hline P66 & Time-resolved VUV luminescence spectroscopy ${ }^{3}$ & $\mathrm{BM}(12 \mathrm{mrad})$ & $4 \mathrm{eV}-40 \mathrm{eV}$ \\
\hline
\end{tabular}

\section{REFERENCES}

1. E. Weckert, K. Balewski, W. Brefeld, W. Decking, W. Drube, H. Franz, U. Hahn, J. Pflüger, H. SchulteSchrepping, M. Tischer, and J. Schneider, AIP Conf. Proc. 705, 73-76 (2004).

2. K. Balewski, M. Bieler, J. Keil, A. Kling, G. K. Sahoo, and R. Wanzenberg, "PETRA III upgrade" in Proc. $2^{\text {nd }}$ Int. Particle Accelerator Conf. (IPAC'11), San Sebastián, Spain, September 4-9, 2011, pp. 2948-2950.

3. M. Bieler, M. Ebert, L. Fröhlich, J. Keil, J. Klute, G. Kube, G. K. Sahoo, R. Wanzenberg, "Status of the recommissioning of the synchrotron light source PETRA III" in Proc. $6^{\text {th }}$ Int. Particle Accelerator Conf. (IPAC'15), Richmond, VA, USA, May 3-8, 2015, in press.

4. A. Schöps, T. Ramm, M. Tischer and P. Vagin, "Recent undulator developments at DESY" (SRI 2012), J. Phys.: Conf. Series 425, 032002 (2013).

5. A. Schöps, P. Vagin, and M. Tischer, "Properties of the Insertion Devices for PETRA III and its Extension", these proceedings.

6. H. Schulte-Schrepping, M. Degenhardt, H.-B. Peters, U. Hahn, J. Heuer, and M. Hesse, "Status of PETRA III photon beamline frontends and optical systems" (SRI 2012), J. Phys.: Conf. Series 425, 042005 (2013).

7. H. Schulte-Schrepping, M. Hesse, M. Degenhardt, H. Krüger, R. Peters, H.B. Peters, and B. Steffen, "Photon Beamline Frontends for the PETRA III Extension Project", these proceedings.

8. P. Kristiansen, J. Horbach, R. Döhrmann, and J. Heuer, J. Synchrotron Radiation (accepted, 2015). 